\title{
The Role of Social Media during Queensland Floods: An Empirical Investigation on the Existence of Multiple Communities of Practice (MCoPs)
}

\author{
Ashir Ahmed \\ Swinburne University of Technology \\ Melbourne, Australia \\ azahmed@swin.edu.au \\ Sukunesan Sinnappan \\ Swinburne University of Technology \\ Melbourne, Australia \\ ssinnappan@swin.edu.au
}

\begin{abstract}
The notion of communities getting together during a disaster to help each other is common. However, how does this communal activity happen within the online world? Here we examine this issue using the Communities of Practice (COP) approach. We extend CoP to multiple CoP (MCoPs) and examine the role of social media applications in disaster management, extending work done by Ahmed (2011). Secondary data in the form of newspaper reports during 2010 to 2011 were analysed to understand how social media, particularly Facebook and Twitter, facilitated the process of communication among various communities during the Queensland floods in 2010. The results of media-content analysis along with the findings of relevant literature were used to extend our existing understanding on various communities of practice involved in disaster management, their communication tasks and the role of Twitter and Facebook as common conducive platforms of communication during disaster management alongside traditional communication channels.
\end{abstract}

Keywords: Communities of Practice, Social Media, Disaster Management 


\section{Introduction}

Unprecedented utilisation of social media applications, especially Twitter and Facebook, has been observed during and after the Queensland (Australia) floods in the year 2010-2011. There are many success stories in which social media applications acted as saviour during such crises (Yanay, Benjamin et al. 2011; Crawford 2012; Rive, Thomas et al. 2012). Disaster management agencies, especially Queensland Police Services (QPS), used these media as their strategic tools to disseminate relevant information during and after the Queensland floods. Local communities also relied significantly on these tools to get the latest flood information and to keep in touch with friends and families (Taylor, Wells et al. 2012).

Currently there are a number of studies available that discuss various aspects of social media usage during the Queensland floods (Cheong and Cheong 2011; Bird, Ling et al. 2012; Taylor, Wells et al. 2012). In general, these studies look at particular social media applications such as Twitter or Facebook and examine the way they were used (Bruns and Liang 2012). Further, there are a few studies available that shed some light on the types of participants involved in the communication process (Cheong and Cheong 2011). In particular, Ahmed (2011) published a study that laid down a foundation for future research by investigating the communication processes that occurred within social media platforms during Australian natural disasters. In addition, a conceptual framework was also proposed by Ahmed which explored the nature of interaction and the ability of social media in facilitating the functional needs of interaction involving disaster management agencies and communities (before, during and after a disaster). However, the framework proposed by Ahmed did not identify components such as business organisations participating in disaster management alongside communities and agencies. The existence of other communities within disaster management is critical in ensuring that there is less overlap in efforts in handling a disaster. Efficient symbiotic relationships would be considered ideal between different communities but this could be far from reality as noted by the Victorian Bushfire Royal Commission (VBRC, 2010) and as discussed in Sinnappan et al (2010). However, an investigation in this direction would be considered a critical step toward achieving this; and understanding the different roles assumed by these communities during a disaster is the main motivation of this study. It is hoped that the findings of this study will help communities to understand their roles and boundaries in order to be efficient and resource-smart.

Thus, considering the Queensland floods as a case study and amalgamating it with the recommendations of Ahmed's work, this paper performs media-content analysis (newspaper reports) and attempts to extend the understanding on the key participants involved in the communication process, their level of interaction and their associated communication tasks. Here, we argue with justification that each key participant and their peers act as a community of practice (known as CoP from here on). In this light, we explore the existence of multiple Communities of Practice (known as MCoPs from here on) who work together in parallel during a particular disaster. The analysis of MCoPs is then used to revise the conceptual framework originally presented by Ahmed (2011). To achieve this, the second section of this paper is designed to discuss related work within this domain followed by the introduction of COP and a discussion on the conceptual model. The next section will cover methodology which includes data collection and analysis while the next section will have detailed analysis of participating communities (MCoPs) and their activities during disasters. Finally, we conclude the paper and offer future research directions.

\section{Related work}

The Queensland floods (in 2010-2011) have attracted considerable attention from 
researchers as well as practitioners. There are many articles that cover various aspects of the Queensland floods, especially the use of social media applications such as Twitter and Facebook.

An interesting study was published by Cheong and Cheong (2011) that conducted a social network analysis on tweets during Australian floods during 2010-2011. In the context of Australian floods this is a valuable study, as it highlighted the key actors (categorised as local authorities, political personalities, social media volunteers, traditional media reporters and members from non-profit, humanitarian and community associations) and their effectiveness during the communication process. Significant information disseminated by these actors was also discussed. Since this study primarily focuses on the use of Twitter during Australian floods, the findings could not be generalised. Moreover, this research does not address the reasons (communication tasks) different actors need to communicate during Australian floods. Bruns and Liang (2012) also studied the use of Twitter during crisis communication. This study claims that emergency services are successfully using Twitter to inform the public about current developments, and are increasingly attempting to source first-hand situational information from Twitter feeds. A flexible and reliable research infrastructure is also developed for tracking and analysing Twitter feeds during natural disasters such as the Queensland floods. However, there is a lack of discussion on the participants (other than emergency services) that may contribute in the communication process and their associated communication requirements. Rive, Thomas et al. (2012) published a comprehensive report on the use of social media in an emergency. This report covered various aspects of social media usage during two notable disasters - the Christchurch earthquake and the Queensland floods. This report addressed issues like the communication tasks that need to be performed during emergencies and the contributing factors in the optimal use of social media in emergencies, and thus proposed a best-practice guide for the use of social media in emergencies. However, this report fails to lacks in segregating the key participants of the communication process and groups the communication tasks according to those participants. Taylor, Wells et al (2012) articulated the ability of social media to provide access to timely public safety related information from formal and informal sources during natural disasters. According to Taylor, Wells et al (2012), social media enables connectedness both to loved ones and the broader community, providing reassurance, support and routes to assistance.

Collectively, the studies discussed above highlighted the significance of social media during disaster management (in general) and in the Queensland floods (in particular). The majority of these studies performed content analysis on the data extracted from social media applications such as Facebook and Twitter to study their pros and cons during disastrous situations. However, none of these studies investigated the distinct roles played by various participants involved in the communication process of disaster management. It is believed that understanding these roles could be very useful for all participants to efficiently interact and achieve their respective objectives. This would, especially, help the disaster management authorities to play their role better. To the best of our knowledge, one of the few studies addressing this issue was Ahmed's (2011) work where he proposed a conceptual framework that identified (i) the key participants, (ii) their level of interaction (such as agency to agency, agency to community and community to community interaction) and (iii) their associated communication tasks during disasters. It was noted that interaction and activities among similar-natured agencies as mentioned above mimic Wenger's (1998) CoPs. The concept of CoPs found in social media during disasters is a relatively new concept but worth investigating as mentioned before. Thus we will discuss this phenomenon and 
The role of Social media during Queensland floods / Ahmed et al.

examine the interactions between CoPs more closely via a case study.

\section{Communities of Practice in Disaster Management}

Wenger's (1998) community of practice (CoP) has been widely cited in studies relating to communal learning approaches, in particular how a community interacts and engages with its members for the purposes of learning for existence. The three outstanding dimensions that are commonly referred to as part of CoP are (i) domain, (ii) community and (iii) practice. Domain is referred to as the subject or reason that motivates the community to interact in the first place. It could be born out of shared interest which propels the community to come together to share and sustain the domain. Here, this could be related to disaster management or education as cited in Dufty (2011). The second dimension, community, relates to the activities undertaken to maintain relationships and to enhance social capital (Coleman, 1988). This would translate to how members exchange information and support each other as a communal group. Activities such as discussions, meetings, forums including blogs, social media and other forms of cognitive learning with regards to disasters could be included. The final dimension, practice, refers to the premise that members of a particular CoP are practitioners and are not merely an interest group. This would mean that members of CoP are communal members who have sustained practice in a domain they are part of. Wenger (1998) denotes that the combination of these three dimensions forms a CoP.

In view of this paper, the notion of disaster management aligns itself well with CoP especially considering how different agencies in the social media realms come together in times of crisis. Each agency can be seen to have their respective domain, community and practice in terms of disasters, whether it is mitigation, response or recovery stage. Though these stages are not mutually exclusive it can be readily seen how agencies function and overlap in their own right. The various activities undertaken by these agencies are evidently supported by social media. Social media has become a platform for CoPs to sustain their existence and this is evident from the increased uptake of social media during disasters (Hughes and Palen, 2009). In support, Dufty (2011) noted that currently there are many communities that are able to participate in communal activities to educate, communicate and engage (ECE), citing the Social Media 4 Emergency Management (SMEM) group which is better known as \#smem within the Twittershpere. As noted earlier the discussions in SMEM are not always monopolised by a group of people. The community is often joined by academicians, researchers and others sharing the same passion, that is, disaster management. This demonstrates multiple CoPs (MCoPs) coming together to discuss topics with similar relevance, in this instance using the hashtag \#smem.

Formation of such MCoPs has been encouraged indirectly by government agencies to build better awareness and community resilience. Examples of MCoPs in action during disaster are increasingly obvious. After the Japan earthquake and tsunami, social media were seen facilitating various organisations, both formal and informal, to locate people and disseminate public alerts apart from various disaster recovery activities (Hjorth and Kim 2011). Similar findings were echoed during the 2011 Victorian and Queensland floods. From the discussion above we can say that these agencies are not only communicating with themselves but also across to other groups. As CoPs each of them are reaching out in social media while performing their role. This can be illustrated by Figure 1 below that is referred to as the conceptual model. Figure 1 shows that Disaster Management agencies are communicating with Business organisations and Communities and vice versa. To the best of our knowledge, this paper will be one of the first to examine the 
interactions amongst these CoPs. A further contribution will be made by examining the existence of MCoPs and how they symbiotically communicate and play their role. Thus to examine the aforementioned formation and activities of MCoPs, we will build upon Ahmed's (2011) conceptual framework by performing media-content analysis of newspaper reports. This is also done to better understand the role of social media during the Queensland floods. Details on the conceptual model, research methodology - including the case and method for data collection used in this research - are discussed below.

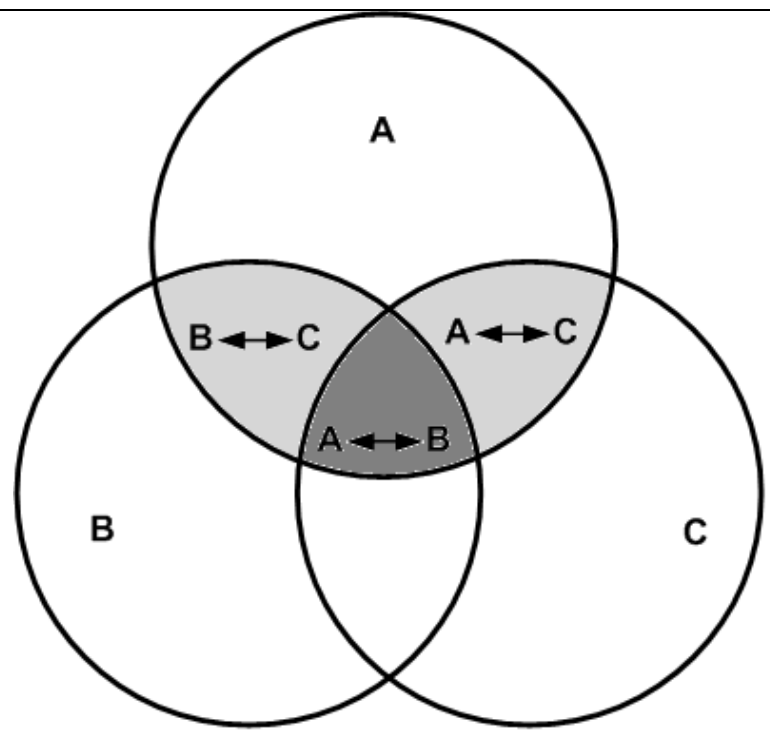

A: Disaster Management Agencies, B: Business Organizations, C: Communities

Figure 1 - Existence of MCoPs and their interactions

\section{Conceptual Model}

Ahmed (2011) proposed disaster management agencies and communities as the two main actors of the communication process during disaster management. The interaction and associated communication between both parties were also defined as part of Ahmed's work. Though this study agrees with his work, it was also articulated that the communication process of disaster management involves more than two parties i.e. disaster management agencies (represented as A), business organisations (represented as B) and communities (represented as C). In this light, this study proposes that $A, B$ and $C$ form 'communities of practice', having established communication tasks performed during their interaction with each other. It needs to be noted that this framework is intended to serve as a conceptualisation of the existing relationships between the three different communities, as mentioned above. The authors have, from the initial analysis, found that all three communities interact with each other at various levels specific to their roles. More details on such communities, that is $A$, $B$ and $C$, are given below: 


\section{Disaster Management Agency (A)}

"A" refers to disaster management agencies (including government based and nongovernment organisations) which are involved in either one or all phases of disaster management. Examples of these agencies include but are not limited to police, fire brigade, ambulance, State Emergency Services and the Country Fire Authority. In context of disaster management, these agencies $(A)$ interact with other agencies (represented as $A \leftrightarrow A$ ), business organisations (represented as $A \leftrightarrow B$ ) and with communities (represented as $A \leftrightarrow C$ ).

\section{Business Organisation (B)}

" $B$ " refers to the organisations that provide services and/or products to different people and organisations during the disaster management life cycle. Some of these organisations directly charge to their customers for their services while others may generate revenues from other

avenues such as sponsorships, grants and/or donations. Examples of these organisations include but are not limited to insurance companies, weather bureaus and news agencies. During disaster management, these organisations interact with other businesses (represented as $B \leftrightarrow B$ ), disaster management agencies $(B \leftrightarrow A)$ and with communities $(B \longleftrightarrow B)$.

\section{Communities (C)}

"C" refers to the group of people who (i) are affected by disaster or (ii) interact with people who are affected by a disaster. Based on the nature and scale of disaster, the affected community may contain a varying number of people. These communities interact with each other (represented as $\mathrm{C} \leftrightarrow \mathrm{C}$ ), with disaster management agencies (represented as $C$ $\leftrightarrow A$ A) and with business organisations (represented as $\mathrm{C} \leftrightarrow \mathrm{B}$ ).

\section{Methodology}

\section{The Case}

During December 2010 to January 2011, the north eastern Australian state of Queensland was severely hit by floods (called the Queensland floods) and later on by cyclone Yasi. This situation caused three quarters of Queensland to be declared as a disaster zone. The affected area of 500,000 sq. km comprised 70 towns and 67 suburbs. This was one of the deadliest and most expensive disasters that this state has experienced over the years. The Queensland floods resulted in the loss of 35 precious lives while the infrastructure loss was around AUD 20 billion - that is, $1.5 \%$ of the annual GDP of Queensland. It was estimated that there were close to $35,000-40,000$ homes damaged or destroyed, while communities were directly affected apart from severe damage to businesses and industries. For instance, AUD 2.55 billion in insurance claims $(56,200)$ were lodged (Honert and McAneney 2011). The hoteliers in Cairns reported occupancy rates of just $50 \%$ as compared to the previous year, while the Gold Coast reported figures of about $60 \%$. This situation placed an extra burden on the state government, which announced a support package of AUD 10 million to the tourism industry. Similarly, the government announced a one-off tax to raise AUD 1.8 billion of the AUD 5.6 billion needed for reconstruction. In short, the Queensland floods had greatly impacted the general public, groups, businesses and the government of Queensland.

Although the loss and devastation caused by the Queensland floods was undeniable, the resilience of communities and the work (especially the response and rescue activities) conducted by various disaster management agencies was quite magnificent. As a part of the disaster management policies, the participating disaster management agencies made the best use of their available resources to deal with the devastation caused by these floods. 
Special attention was given to assure the effective, reliable and timely flow of disaster related information to the communities and businesses. There was lots of media coverage (such as newspaper, radio and TV) around that time that emphasised the role of effective flow of information during the Queensland floods. This study looks at newspaper reports that highlighted the ways in which social media was used during the Queensland floods.

\section{Newspaper Selection}

Large numbers of newspapers are printed in Australia - including 12 major national or state/territory daily newspapers, about 35 regional daily newspapers, 9 Sunday newspapers, and almost 500 weekly or twice-weekly regional, rural and suburban publications. They come in either tabloid or broadsheet format and vary in circulation size. In Australia, Saturday and Sunday editions of major newspapers are more widely read than weekday editions. With the proliferation of information technology and internet, major Australian newspapers are now available in electronic as well as their traditional paper format. These newspapers form the information backbone for the Australian public, covering the most essential and relevant information. According to Macnamara (2003), the sampling of media content analysis comprises three steps:

i- Selection of media forms (i.e. newspapers, magazines, radio, TV etc)

a. Data is collected from electronic versions of five Australian newspapers. These newspapers include both regional and national newspapers. The names of the selected newspapers, along with their URLs, are mentioned in the section below.

ii- Selection of issues and dates (the period)

a. Newspapers published over the period of around six months (from December 20, 2010 to
June 1, 2011 are selected for this research. Newspapers published outside the abovementioned period are not considered for this research.

iii- Sampling of relevant content from within those media

Purposive sampling is used where the units (newspaper articles) investigated are based on the judgement of the researchers. As purposive sampling is prone to researcher's bias, special emphasis was given to minimising the bias of the sampling process by following clear criteria based on the theoretical framework.

\section{Data Collection Method}

Five top (by circulation) Australian newspapers were selected to represent both regional and national news coverage. All five newspapers are broadsheets and politically independent; while each newspaper might have its political leanings, none of them are explicitly affiliated with a political party in Australia. Data was also collected from the electronic versions of the selected newspapers. Two online national newspapers selected for this research include:

i- The Australian, available at http://www.theaustralian.com.au/ and

ii- $\quad$ The Sydney Morning Herald, available at http://www.smh.com.au/

Further to the above, three regional online newspapers that were included were:

i- The Queensland Times, available at http://www.qt.com.au/

ii- Gold Coast Bulletin, available at http://www.goldcoast.com.au/ and

iii- Brisbane Times, available at http://www.brisbanetimes.com.au/

\section{Article Selection}

A search was conducted including different variations of keywords such as "Social media", "Queensland floods", "Queensland 
The role of Social media during Queensland floods / Ahmed et al.

disaster", "Queensland floods 2010" and/or "Queensland floods 2011" on the newspaper reports published during the period from December 20, 2010 to June 1, 2011. Initially, a purposive method of sampling was used to download 78 newspaper reports which were further scrutinised based on their relevance to the research topic. Consequently, the total number of newspaper reports was reduced to 49 that include only those articles that report on the use of social media especially Twitter and Facebook during Queensland floods.

\section{Data Analysis}

Content analysis has been defined as a systematic, replicable technique for compressing many words of text into fewer content categories based on explicit rules of coding (Stemler 2001). In more contemporary terms, content analysis is a research method that uses a set of procedures to make valid inferences from text (Macnamara 2003). Media content analysis is a specialised subset of content analysis, a well-established research methodology using mass media such as newspaper reports and articles for making inferences by systematically and objectively identifying specified characteristics within the text (Macnamara 2003). This study performed media content analysis on newspaper reports to identify the relevant themes and patterns by using Priori coding. Priori coding technique was found very useful to defuse the criticism of media content analysis that it often fails the test of objectivity because researchers construct the list of issues as they find them in articles. Priori coding design requires that "all decisions on variables, their measurement, and coding rules must be made before the observation begins" (Macnamara 2003).

The overall objective of media content analysis conducted in this research is to capture the evidence on the following three themes to verify the conceptual model that was proposed in Figure 1: i. Participants in the communication process

ii. Level of interaction among various participants in the communication process and;

iii. Key tasks of the communication process

\section{Participants in the Communication Process Along With Their Associated Tasks}

\section{Disaster Management Agencies}

Various types of agencies such as police, ambulance and fire brigade play an important role in disaster management. The critical nature of their roles requires the dissemination of timely, effective and accurate information. During disasters, these agencies form the primary source of disaster information, or at least perform a central role by liaising with other participants in the communication process. In the context of disaster management agencies, following are the communication tasks that emerged from the review of related literature and media content analysis of newspaper reports.

\section{Coordination and Collaboration}

According to Quarantelli (1986, p. 1),

"Successful disaster management results from organizations coping well with the communication process, the exercise of authority and the development of coordination".

In addition, a wealth of social and behavioural research presents coordination as a major challenge among the individuals, groups and agencies that respond to disasters (McEntire 2002). Similarly, effective collaboration among disaster response parties including the local population, local government authorities and humanitarian organisations is an essential part of natural disaster management (Oloruntoba, 2005; McEntire, 2002). Despite the fact that the importance of coordination in disaster management has been reported 
in literature, various emergency studies highlight insufficient coordination among responding agencies (McEntire 2002). The involvement of a vast number of agencies can create obstacles to coordination efforts at the field level. The participating agencies will have their own operating methods and sometimes there is competition amongst them for the limited resources (Long and Wood, 1995). Nevertheless, successful execution of a disaster management plan is based on appropriate management and coordination of various agencies operating during a disaster (Ahmed 2011).

In Queensland, the disaster management arrangements are made up of several key management and coordination structures through which the functions of disaster management for Queensland are achieved (Queensland Government 2012). The principal structures that make up Queensland's disaster management arrangements are:

i- Disaster management groups operating at local, district and state levels which are responsible for the planning, organisation, coordination and implementation of all measures to mitigate/prevent, prepare for, respond to and recover from disasters.

ii- Coordination centres at local, district and state levels that support disaster management groups in coordinating information, resources and services necessary for disaster operations.

iii- State government functional agencies through which the functions and responsibilities of the state government in relation to disaster management are managed and coordinated (Queensland Government 2012).

The Queensland disaster management arrangements recognise that disaster management is a whole-of-government issue involving shared responsibilities between the state and local government, and involving
Commonwealth support and incentives to achieve national congruity (Angus 2011). Consequently, the purpose of Queensland's disaster management structure is to coordinate all the resources necessary for planning and managing the consequences of disasters and act as a guideline for the government on issues related to disaster management (Angus 2011).

The recent event of the Queensland floods posed a real challenge for the disaster management agencies operating at local, district and state level. The impact and devastation caused by these floods was far beyond the capacity of any single disaster agency. Since the disaster agencies operating in the affected areas were focusing only on a particular subset of the overall disaster management process, effective and timely communication and coordination among them was vital. Therefore, several communication tools were utilised by these agencies to communicate with each other. Among several other tools for communication, social media, especially Facebook and Twitter, emerged as important communication tools during the time of crisis (Bird, Ling et al. 2012; Bruns and Liang 2012). The didactic role played by these tools attracted a lot of attention from disaster management agencies, community members and other businesses working together and supporting each other to deal with one of the state's biggest natural disasters. During the Queensland floods, several Facebook pages and Twitter hashtags (such as \#qldfloods, \#bnefloods, \#thebigwet, \#bnefloods, @couriermail and @brisbanetimes) proved to be the main outlets for information sharing among various disaster management agencies (Chessell 2011). One of the success stories of using Twitter came into being when the Queensland Police Service (QPS) started issuing regular media releases to the QPS Facebook page and linked to these on Twitter (Charlton 2010). The information available through these avenues was valuable not only to other disaster management agencies but also for volunteer groups and individuals who were in the 
The role of Social media during Queensland floods / Ahmed et al.

affected area to help people, and for the communities who were at risk. Large number of organisations and individuals used the information that was coming through these social media channels. For instance, in the 24-hour period following the flash floods, the number of "likes" on the QPS Facebook page increased from approximately 17,000 to 100,000 . The same day the QPS Facebook page generated 30 million post impressions, equating to 450 post views per second over the peak 24-hour period (Charlton 2010). The significance and usefulness of social media was acknowledged even after the end of the Queensland floods. Consequently, the creator of the Facebook page "Cyclone Yasi Update" has been called in by the government to discuss using Facebook as a disaster management tool in future (McBryde 2011).

\section{Education}

A majority of disasters have huge and enduring impacts on human lives and societies (Ahmed and Sugianto 2012). In order to minimise the consequences of such events, it is important to prepare and develop resilient communities by educating them with appropriate and up-to-date information required to deal with disasters (Paton and Johnston 2001). Traditionally, disaster management agencies are used to conduct seminars and workshops to educate communities about disasters and help people in preparing their emergency response plans. Furthermore, members of the community also share their knowledge and help each other in preparing for disasters (Ahmed and Sugianto 2012). With the technological proliferation over the last few years, especially the use of social media applications such as Facebook, Twitter and YouTube, the process of education and virtual communication has been taken to new heights by making it easy and effective (Riddell, Rock et al. 2010). Currently there are numerous pages on Facebook and countless videos available on YouTube that discuss disasters and how to deal with different types of disasters. Another aspect of using social media for disaster preparation was revealed when people affected by the Queensland floods shared their personal experiences and provided information that was beneficial to others. This was noted by Skyes (2011) in his study, for instance,

"It was no longer a news event that people were passing on but they were providing practical information on how to flood proof your house or after the flood had happened how to clean up"..

\section{Information Dissemination}

The majority of disaster management agencies are expected to provide necessary information to their communities. Generally, such information contains regular "updates" rather than a specific "warning" or "alert" on a disaster such as the regular "weather update", "traffic alert" and "news headline" (Ahmed 2011). This sort of information helps people to become aware of up-to-date information about their environment. Nowadays, social media applications, especially Facebook and Twitter, are used as a primary tool - along with traditional media such as TV and radio - to share and disseminate the latest information to the broader audience (Dennis and Valacich 1999).

Facebook and Twitter played a valuable role in disseminating important information related to the Queensland floods. It has also been observed that various disaster management agencies used these tools as part of their strategy to ensure efficient, consistent and reliable communication with the potential audience. For instance,

"Through their QPS Media Twitter account, Queensland police staff provided timely updates directly from the Queensland premier's situation meetings"

said Associate Professor Axel Bruns, from the Queensland University of Technology (Burgess 2012). The Queensland Police Service was one of an increasing number of public service organisations using social 
media as a way to disseminate accurate information immediately at the time of the Queensland floods.

QPS “acts as centralised clearing house for disaster-related information through Facebook and Twitter as soon as it becomes available, including details on behalf of other departments and authorities" (Queensland Police 2011).

Overall, Twitter proved to be a popular medium for organisations and people to disseminate information using the \#qldfloods, \#bnefloods and \#thebigwet hashtags, which link a series of individual tweets under a single subject. According to Twitter tracking service Trendsmap (www.trendsmap.com), \#qldfloods was among the top 10 Australian tags in that week while several other floodsrelated topics (\#bnefloods, @couriermail and @brisbanetimes) made it onto its "hot topics around the globe" list (Chessell 2011). Further to the significance of Twitter,

"Facebook groups also emerged with a nearinstant following", said Dr Deanne Bird, a research fellow at Risk Frontiers - Natural Hazards Research Centre at Macquarie University (Taylor 2011).

These groups sourced data from agencies such as the Queensland Police and the Bureau of Meteorology as well as near-realtime information from the public. In addition, several Facebook sites were observed during the Queensland floods that offered great value in the dissemination of important information such as news of people's whereabouts, help in reuniting pets with their owners and up-to-date information on flood zones (Howell 2011).

\section{Issue Warnings}

Further to the regular "updates", accurate and timely warnings play a significant role in disaster management. Despite the presumed ubiquity and power of advanced technologies, the issuance of accurate and timely warnings was generally not witnessed in most of the natural disasters such as the Indian Ocean tsunami of 2004 (Samarajiva
2005). Contrary to the critical nature of accurate warnings, it is worth noting that false disaster warnings could have significant impact on people. During the Queensland floods, various disaster management agencies used social media such as Facebook and Twitter as their key communication tools to issue warnings and alerts on upcoming floods. For instance, Queensland police used Facebook and Twitter to deliver safety messages and updates, helping to significantly broaden their public information campaign about floods (Queensland Police 2011). One of the best examples of Twitter use during the floods was by the Queensland Police Service Media Unit. Their @QPSMedia account became a major source of information for Queenslanders, sending out reliable, fact-checked updates about the spread of the water, and where support services could be found. Tweets from QPSMedia included vital warnings such as

"The Riverside Expressway in Brisbane CBD is now closed. Please avoid driving through Brisbane. \#thebigwet \#qldfloods" (Knaus 2011).

As a lesson learnt from previous disasters, the Police Service Media Unit created a "MYTHBUSTERS" series of tweets: intervening before misinformation could spread through the network. The vast majority of tweets sent by and to QPS focused on direct information: which roads were passable, when to leave homes, where basic food could be found for communities that were cut off from services. However, Twitter also carried false reports, including the suggestions that Brisbane's CBD was being evacuated and public transport was shut down. These myths were debunked by tweets from the Queensland Police Media Unit (QPS media report). Further to the role of Twitter in issuing timely warnings and countering false information, the Queensland Police Services Facebook group $(162,000$ followers) was also a rich source of evacuation warnings, local conditions and community feedback. Its warnings were mirrored in its Twitter feed. The Queensland 
The role of Social media during Queensland floods / Ahmed et al.

and Toowoomba flood groups, also on Facebook, offered forums for people searching for loved ones, evacuating, seeking food, water and shelter, and pinpointing floodwaters (Griffith 2011).

\section{Business Organisations}

Natural disasters such as floods leave their impacts on anything that comes in their way. Homes, businesses, government or nongovernment organisations, all have to face the consequences of natural disasters. Directly or indirectly, the whole society suffers from a disaster. Similarly, the consequences of a disaster may impinge on various businesses even after the disaster is apparently over. For instance, the Queensland floods not only affected hundreds of individuals but also a large number of businesses and industries such as insurance, tourism, hotels and agriculture, in particular. One in five businesses in Queensland has had to close as a result of the floods due to full or partial water inundation, loss of power or being cut off from their business. More than half of the businesses (55.17\%) who indicated that they had been fully or partially inundated by flood water had buildings affected. Many also had plant, equipment (43.10\%) and stock $(44.83 \%)$ affected. Two in five businesses had office furniture and equipment affected and one in five had motor vehicles affected. Above all, a majority of businesses lost a considerable part of their revenues as their customers were affected by the floods.

Regular conduct of business tasks during disasters requires effective communication with disaster management agencies (in order to get updates about a disaster situation) and with their clients (to gain awareness of their situation and to provide them with the required information about a disaster situation). During the Queensland floods, businesses found social media was an important channel to communicate with disaster management agencies and with their clients. In the context of business organisations, the following communication tasks are found to be relevant.

\section{Collaboration and Situational Awareness}

Social media tools offer great support for collaboration and information sharing among various organisations and businesses. Frequently changing circumstances during the Queensland floods posed a huge challenge to keep up to date with their clients and disseminate relevant and timely information. For instance,

"Insurance companies have looked to social media, online and collaboration tools to help them stay connected with customers" according to chief information officers who discussed this at a recent event in Sydney. Zurich Australia CIO Scott Watters said

"Collaboration tools [such as social media] were important when trying to keep in contact with customers who were experiencing the devastation of the Queensland floods".

Watters further stated that it is important for their business to have situational awareness of their customers. According to him,

"We were watching TV and we saw a house just float out the river and the letter box was still attached to it so we thought how are we going to contact that customer?"

On the same line, Allianz Australia ClO Steve Coles spoke about the importance of situational awareness of their clients as:

"What did that mean from a business and a customer perspective? It meant that we were able to identify the customer, identify the risk and initiate the action of recovery for that customer far quicker than we would have been able to do normally and we hear far quicker than some of our competitors were able to do."

He further stated that:

"Social media gives customers and their insurers a way to engage more with each another. I think social media is a two-way 
stream now, it's a bilateral discussion," Coles said.

"I think this is a great opportunity for the insurance companies to continually reach out to those people that they have already communicated with and those people who are communicating with them."

Maintaining customers' trust is also important, Coles said.

"Once that trust is created it's up to the insurance companies to then maintain it, and they have got the facilities to do it - there's the opportunity [for companies] to run that bilateral two-way communication to keep their customers connected to their business."

Other than insurance companies, several other businesses also used social media during the Queensland floods. For Tourism Queensland,

"Social media emerged as a driving advertising force for the $\$ 6.9$ million campaign".

The key purpose of this campaign was to update people about the tourist activities in Queensland and counter any rumours about the post-flood situation. In circumstances where traditional communication channels such as phones were not up to scratch, social media offered an effective channel to send their message out and attract people back toward Queensland. According to Midena (2011):

"The big problem at the moment is that our phones have stopped ringing. This campaign is a great way let the public know that Queensland is still open for business".

\section{Alerts and Warnings}

During the Queensland floods, another important use of social media by business organisations was to disseminate important information including alerts and warnings about the upcoming disaster. In contrast to generally issued warnings by various disaster agencies, it was found that business organisations issue specific warnings and action plans to specific people (customers).
During the Queensland floods, when rumours circulated about certain areas being inaccessible, dedicated users quashed unconfirmed rumours and encouraged everyone to re-confirm their facts. Business organisations used five dominant types of Twitter updates during the Queensland floods, including alerts and warnings, direct information, media sharing, eyewitness reports and wider discussions and community reactions, especially from the customers (Crawford 2012).

\section{Communities}

Effective and timely communication among community members and disaster management agencies plays a significant role before, during and after a disaster. For instance, before a disaster, community members can help each other in preparing for disasters by sharing their information, expertise, resources and support. Similarly, during or just after a disaster, community members are generally the first responders to the victims (Sykes 2011). This paper highlights three needs for interaction among community members and discusses how the use of social media can facilitate them.

\section{Queries and Feedback}

A range of social media usage has been reported in various newspapers. It has been reported that people used Twitter and Facebook to ask specific questions about the flood situation in a particular area, to ask for help and also to provide feedback to the relevant agencies. This has been reported in other studies involving disasters in Australia (Sinnappan et al 2010). The interactivity offered by social media applications, which allows its users to ask and respond at the same time, makes it more popular than traditional communication channels; especially during time-critical situations like disasters. According to Taylor (2011),

"Facebook was more useful than government websites and media reports during the Cyclone Yasi emergency in Queensland." 
The role of Social media during Queensland floods / Ahmed et al.

Norms and conventions develop quickly on Twitter during a crisis. During the Queensland floods, people consistently relayed critical updates from emergency services, with up to $60 \%$ of messages being "retweeted". Many included links to external sources, with almost $40 \%$ of messages containing links to further information. Some Twitter users dedicated themselves almost exclusively to retweeting urgent messages, acting as amplifiers of emergency updates and increasing their reach (Crawford 2012).

\section{Communication}

Interaction in terms of communication among community members remains vital in all phases of disaster management. Widmer (2003) indicated that for the success of relief efforts, the participating agencies should give importance to local information and cooperate with the local community. Recently it has been observed that social media played a significant role in keeping the communities in touch with each other. Availability of various social media tools such as Facebook and Twitter on mobile phones makes it more convenient for people to stay connected anytime and anywhere. Moreover, social media has proved an effective, reliable and preferred medium for communication both during normal as well as unusual working conditions caused by various disasters (Hughes, Palen et al. 2008).

Fellow QUT researcher Dr Jean Burgess reported that

"During the Queensland floods a large number of people used social media to share critical disaster information with each other" (Burgess 2012).

For instance,

"During the week of 10 January 2011, some 15,000 users participated in the \#qldfloods hashtag on Twitter. The primary use of such tweets was to share news, advice, photos and videos of the inundation."

Such communication among community members proved significant
"In enabling local communities to stay informed, share their own knowledge and experiences, and to co-ordinate flood protection and clean-up activities" (Burgess 2012).

An interesting aspect of the usefulness of social media during the Queensland floods emerged when a survey conducted by researchers at Risk Frontiers - Natural Hazards Research Centre at Macquarie University revealed that during the Queensland floods:

"People ranked community Facebook groups higher than government and media Facebook groups and websites in terms of accuracy, usefulness and in up-to-date information" (Taylor 2011).

\section{Moral / Emotional Support}

During and after a disastrous event, one of the key functions of communication media is to fulfil people's needs for emotional support, companionship and community ties (PerezLugo 2004). Individuals actively look for emotional support from the media, which provides the community with ties (or "communication bridges") between its isolated members within the time period defined by the impact of the natural event (Perez-Lugo 2004). Supporting behaviour is demonstrated when people converge with the primary purpose of expressing thanks to disaster respondents and lending moral support to disaster victims. With the proliferation of online tools and applications, the same expressions of support can be found online. Over the last few years, various social media applications have proved to be effective tools to provide moral and emotional support to the victims of a disaster (Hughes, Palen et al. 2008). Fans of a specific cause on Facebook, followers of a specific tweet on Twitter and viewers of a specific video on YouTube can be seen to demonstrate support for victims of a particular event. An Australian academic has praised the increasing use of social media during disasters, saying there had been a "beautiful display of humanity" on Facebook 
during recent catastrophes. She said that interviews with people who established Facebook sites to help victims of Queensland's devastating floods in January had demonstrated that a "sense of real community" existed in the virtual space. She further articulated that:

"That was the thing that struck me... this beautiful display of humanity and generosity and a sense of "I don't know you but I want to be able to help". If that's what Facebook is providing and social media is providing people with in times of terrible anguish, I think it's a fantastic resource." (Howell 2011).

Social media has proved to be a powerful tool in the disaster relief effort in Queensland and in offering moral support to the victims,

"With sites such as Facebook and Twitter helping to co-ordinate temporary housing, provide vital police updates and record firsthand experiences of the disaster."

For instance, in one case, a Facebook page was created to help connect flood-affected Queenslanders with others wanting to provide temporary accommodation and shelter (Knaus 2011). Mrs French, who lives in Adelaide, set up the page on Tuesday, and there have since been more than 500 offers of accommodation across Queensland.

"These are people offering a spare room, or a sofa, a shelter for animals, even meals for people," Mrs French said.

"They're listing their suburbs; the number of beds they've got available and then they're inviting the flood victims to message them privately for address details" (Knaus 2011).

The usefulness of social media during the Queensland floods was further highlighted when this communication media allowed for others to drive fund-raising efforts, including one in Adelaide, where Alison Kershaw tried to drum up support using Twitter.

"We need venue for 200 people for the \#qldfloodsfundraiser, you can run the bar \& guest will bring snacks, any takers? \#adelaide"(Knaus 2011).
During the Queensland floods, it has also been observed that social media triggered various campaigns worldwide to not only offer moral support to the Queensland floods victims but also to organise fundraising activities to contribute to the quick recovery of the affected communities. For instance,

"In London, the campaign was launched by men in top hats holding memo signs; in Hong Kong and Korea by people in scuba diving gear; in Germany they had dozens of Skippy kangaroos jumping through the streets; in addition to the ads [help for Queensland flood victims] popping up in elevators across Sydney and Melbourne" (Midena 2011).

The coverage of the Queensland floods on social media and the number of people throughout the world engaged with this type of medium (social media) stimulated other media outlets to cover this disaster. According to Mr Hayes,

"The story has also been picked up by 270 media outlets across the world, including interest from the UAE, which we haven't seen before".

People from the US, the UK, Germany, Malaysia, and of course Australia expressed their support and best wishes for the victims of the Queensland floods (Midena 2011).

\section{Communication with the Rest of the World}

Since the use of social media is not restricted by geographical boundaries, it facilitates interaction with anyone in the world who is sharing the same media application (Boyd and Ellison 2008). In the context of disaster management, this could have a huge impact on the global community. On one hand, social media are used to update others about what actually is happening at the disaster scene and on the other hand it opens new windows for the people to be in touch with each other and to show their support for those who are affected by a disaster. Social media also helped isolated individuals to feel connected 
The role of Social media during Queensland floods / Ahmed et al.

with the "outside world" (Perez-Lugo 2004). During the Queensland floods, tweets emerged as part of the fabric of the news: locals who posted dramatic mobile videos or messages to twitter suddenly found their materials being broadcast on national television. Tweets during the floods provided "real-time" updates on the unfolding crisis to the rest of the world through social and traditional media (Crawford 2012). During the floods, Twitter provided more than oneway broadcasts: using tweets, people "listen in" and respond, sometimes correcting journalistic errors, offering a hand to those in trouble, and banding together to form volunteer clean-up groups.

\section{Discussion}

The discussion above provides insight on the media coverage (newspaper reports) on the role of social media during the Queensland floods. It was found that dissemination of reliable, effective and timely information is critical during disastrous situations and requires the usage of appropriate media that can facilitate various MCoPS in their communication process and fulfil their communication requirements. It was also observed that each CoP has its own specific set of tasks and preferences of using a specific social media application that is primarily based on the nature of a particular task. For instance, analysis of newspaper reports on the Queensland floods revealed that short and precise messages such as tweets are the most preferred mode of communication in time-critical situations such as during the disasters, whereas long messages such as Facebook posts are widely used in the post-disaster phase. Review of relevant literature and media content analyses employed in this research highlight emerging themes which could be segregated into three main categories including (i) participants involved in the communication process, (ii) their level of interactions and (iii) their associated communication tasks. These findings validated the conceptual model that was presented in Figure 1 and are summarised in Table 1 below: 


\section{Table 1 - Key themes emerged from media-content analysis}

\begin{tabular}{|c|c|c|c|}
\hline $\begin{array}{l}\text { Interaction } \\
\text { Level }\end{array}$ & $\begin{array}{c}\text { Communication } \\
\text { tasks }\end{array}$ & Evidence from literature & $\begin{array}{l}\text { Evidence from } \\
\text { empirical data }\end{array}$ \\
\hline $\begin{array}{c}\text { A-A } \\
\text { Interaction }\end{array}$ & 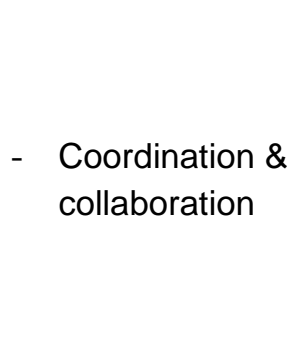 & $\begin{array}{ll}\text { - } & \text { Quarantelli (1996) } \\
\text { - } & \text { Yanay, Benjamin, \& } \\
& \text { Yamin (2011) } \\
\text { - } & \text { Shaluf, Ahmadun, \& } \\
& \text { Mustapha (2003) } \\
\text { - } & \text { Toft \& Reynolds (1994) }\end{array}$ & $\begin{array}{ll}- & \text { Angus (2011) } \\
\text { - } & \text { Bird, Ling, \& Haynes } \\
& (2012) \\
\text { - } & \text { Bruns \& Liang (2012) } \\
\text { - } & \text { Chessell (2011) } \\
- & \text { Charlton (2010) } \\
- & \text { McBryde (2011) }\end{array}$ \\
\hline $\begin{array}{c}\text { B-B } \\
\text { Interaction }\end{array}$ & - Collaboration & $\begin{array}{ll}\text { - } & \text { Ritchie (2004) } \\
\text { - } & \text { Henderson (2007) } \\
\text { - } & \text { Asimakopoulou \& } \\
& \text { Bessis(2010) } \\
\text { - } & \text { Underwood (2010) }\end{array}$ & $\begin{array}{ll}- & \text { Crawford (2012) } \\
\text { - } & \text { Burgess (2012) }\end{array}$ \\
\hline $\begin{array}{c}\text { C-C } \\
\text { interaction }\end{array}$ & $\begin{array}{l}\text { - } \text { Communication } \\
\text { - } \begin{array}{l}\text { Interaction with } \\
\text { the rest of the } \\
\text { world } \\
\text { - }\end{array} \\
\text { Moral Support }\end{array}$ & $\begin{array}{ll}\text { - } & \text { Spiegel (2005) } \\
\text { - } & \text { Widmer (2003) } \\
\text { - } & \text { Hughes, Palen, Sutton, } \\
& \text { Liu \& Vieweg (2008) } \\
\text { - } & \text { Perez-Lugo (2004) } \\
\text { - } & \text { Boyd \& Ellison (2008) } \\
\text { - } & \text { Sinnappan et al (2010) }\end{array}$ & $\begin{array}{ll}\text { - } & \text { Burgess (2012) } \\
\text { - } & \text { Taylor (2011) } \\
\text { - } & \text { Howell (2011) } \\
\text { - } & \text { Knaus (2011) } \\
\text { - } & \text { Midena (2011) }\end{array}$ \\
\hline $\begin{array}{c}\text { A-B } \\
\text { Interaction }\end{array}$ & $\begin{array}{l}\text { - } \text { Queries and } \\
\text { Feedback } \\
\text { - Collaboration }\end{array}$ & $\begin{array}{ll}\text { - } & \text { Waugh \&Streib (2006) } \\
\text { - } & \text { Saleem et al. (2008) } \\
\text { - } & \text { Kapucu (2007) }\end{array}$ & $\begin{array}{ll}\text { - } & \text { Taylor (2011) } \\
\text { - } & \text { Midena (2011) } \\
\text { - } & \text { Howell (2011) }\end{array}$ \\
\hline $\begin{array}{c}\mathrm{A}-\mathrm{C} \\
\text { Interaction }\end{array}$ & $\begin{array}{ll}\text { - } & \text { Education } \\
\text { - } & \text { Information } \\
& \text { dissemination } \\
\text { - } & \text { Queries \& } \\
& \text { Feedback } \\
\text { - } & \text { Issue warnings }\end{array}$ & $\begin{array}{ll}\text { - } & \text { McMichael, Campbell- } \\
\text { Lendrum \& Corvalan } \\
(2003) \\
\text { - } \\
\text { Dennis \& Valacich } \\
\text { (1999) } \\
\text { - } & \text { Samarajiva (2005) }\end{array}$ & $\begin{array}{ll}- & \text { Riddell, Rock, \& } \\
& \text { Frangi (2010) } \\
\text { - } & \text { Skyes (2011) } \\
\text { - } & \text { Chessell (2011) } \\
\text { - } & \text { Taylor (2011) } \\
\text { - } & \text { Howell (2011) } \\
\text { - } & \text { Knaus (2011) } \\
\text { - } & \text { Griffith (2011) }\end{array}$ \\
\hline $\begin{array}{c}\mathrm{B}-\mathrm{C} \\
\text { Interaction }\end{array}$ & $\begin{array}{l}\text { - } \begin{array}{l}\text { Situational } \\
\text { awareness }\end{array} \\
\text { - } \quad \text { Alerts and } \\
\text { warnings }\end{array}$ & $\begin{array}{ll}\text { - } & \text { Vieweg, Hughes, } \\
& \text { Starbird \& Palen(2007) } \\
\text { - } & \text { Liu, Palen, Sutton, } \\
& \text { Hughes \& Vieweg } \\
& (2008) \\
\text { - } & \text { Irina, Palen \& Jeannette } \\
& (2008)\end{array}$ & $\begin{array}{ll}- & \text { Midena (2011) } \\
\text { - } & \text { Crawford (2012) }\end{array}$ \\
\hline
\end{tabular}




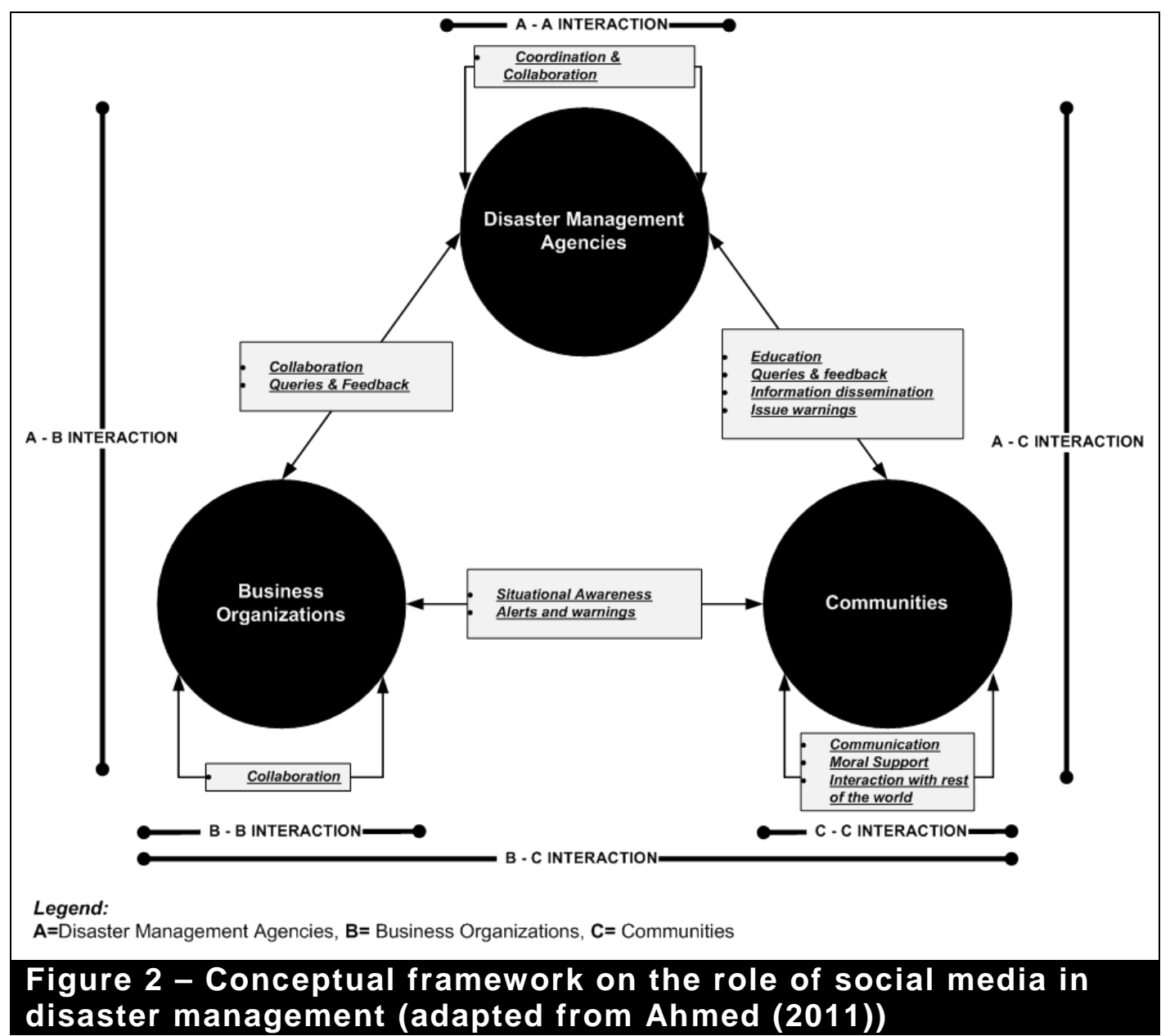

Findings presented in Table 1 were used to revise the original framework proposed by Ahmed (2011). The revised framework shown in Figure 2 highlights the inclusion of business organisations (B) and the way they interact with disaster management agencies (A) and communities (C). In addition, the key communication tasks which need to be performed by $A, B$ and $C$ are also suggested in the revised framework. The updated view of the framework including the participants in the communication process along with their associated tasks is presented in Figure 2 below.

\section{Conclusion}

The significance of this study lies in the analysis of literature and media (newspaper) reports on the role of social media in the communication processes of disaster management. Findings drawn from the media content analysis suggest that social media has become an integral part of media fabric and is capable enough to serve as mainstream media where dissemination of effective, timely and accurate information is critical, such as during crises and disaster situations. Secondary data collected on the Queensland floods provides evidence on critical usage of social media by disaster 
management agencies, business organisations and community members. It was found that these participants are required to interact with each other by using various communication channels, social media in particular. There are also strong indications that the 140 characters of a tweet was the most popular, preferred and commonly used mode of communication among disaster management agencies, business organisations and community members during the Queensland floods. Similarly, Facebook was found to be an effective medium to communicate, particularly during the post-disaster phase. Literature seems to support that social media is increasingly being used as an alternative communication channel (Sinnappan et al, 2010).

The significance of the research findings also lies in the identification of various MCoPs and their associated communication tasks that need to be performed during disaster management. Moreover the significance of social media applications, especially Twitter and Facebook, during the Queensland floods was also discussed. However, there are several areas that require further research. Mapping the characteristics of a particular social media application against a given communication task could be an interesting line of inquiry. This could lead to using more appropriate social media tools for specific tasks that enhance the effectiveness of the overall communication process for disaster management. Further research is also required to empirically examine a wide range of issues such as how a particular phase of disaster management (such as pre-, during and post-disaster) and the nature of disaster (natural, manmade and hybrid) have an influence on the use of a particular social media application.

\section{Limitations and Directions For Future Research}

Despite all the attempts made to undertake a rigorous research, there are still issues that could not be addressed owing to the nature of the research. Some of these issues are as follows:

1- Findings presented in this paper are based on secondary data reported in newspaper articles. In the next stage of this research, data will be collected from primary sources such as by interviewing disaster management agencies, business organisations and members of communities who used social media during disaster management.

2- Newspapers selected in this paper are neither affiliated with any political party in Australia nor biased toward a particular cause. However the information reported in commercial media such as newspapers cannot be guaranteed for comprehensiveness, impartiality and un-baseness on a particular topic.

3- The framework presented in this paper was developed based on the secondary data. This framework needs to be validated by primary data; as such it could be improved in near future when authors engage directly with social media tools to collect primary data. 


\section{References}

Ahmed, A. (2011). Use of Social Media in Disaster Management. International Conference on Information Systems. Shanghai, China.

Ahmed, A. and L. Sugianto (2012). Potential of RFID in Emergency Management: Task-Technology Fit Perspective. Hawaii International Conference on System Sciences. Maui, Hawaii USA.

Angus, D. (2011). "Recent Developments in Emergency Management." Australian Journal of Emergency Management.

Asimakopoulou , E. and N. Bessis (2010). Advanced ICTs for Disaster Management and Threat Detection: Collaborative and Distributed Frameworks, IGI Global.

Bird, D., M. Ling, et al. (2012). "Flooding Facebook - the use of social media during the Queensland and Victorian floods." The Australian Journal of Emergency Management 27(1).

Boyd, M. D. and B. N. Ellison (2008). "Social Network Sites: Definition, History, and Scholarship." Journal of Computer-Mediated Communication 13: pp.210-230.

Bruns, A. and E. Y. Liang (2012). "Tools and Methods for Capturing Twitter Data During Natural Disasters." First Monday 17(4).

Burgess, J. (2012). Qld police praised for flood crisis action The Australian. Brisbane, News Limited.

Charlton, K. (2010). Disaster Management and Social Media - A Case Study. Queensland, Queensland Police Service.

Cheong, F. and C. Cheong (2011). Social Media Data Mining: A Social Network Analysis Of Tweets During The 2010-2011 Australian Floods. Pacific Asia Conference on Information Systems, Brisbane, Australia.
Chessell, J. (2011). Social networking sites reshape crisis coverage. The Australian. Brisbane, News Limited.

Crawford, K. (2012). Twitter can be a saviour in a crisis. The Sydney Morning Herald. Sydney.

Crawford, K. (2012). Twitther can be a Saviour in A Crisis. The Sydney Morning Herald Sydney.

Dennis, A. R. and J. S. Valacich (1999). Rethinking media richness: towards a theory of media synchronicity HICCS. Maui, HI , USA

Griffith, C. (2011). Social media had crucial role in floods: mobile apps offer a wealth of emergency information The Australian. Brisbane, News Limited.

Henderson, C. J. (2007). "Corporate social responsibility and tourism: Hotel companies in Phuket, Thailand, after the Indian Ocean tsunami." International Journal of Hospitality Management 26(1): pp.228-239.

Honert , C. v. d., Robin and J. McAneney (2011). "The 2011 Brisbane Floods: Causes, Impacts and Implications." Water 3: pp.1149-1173;.

Howell, G. (2011). Facebook 'display of humanity' in crises. The Australian. Brisbane, News Limited.

Hughes, L. A., L. Palen, et al. (2008). SiteSeeing in Disasters: An Examination of On-Line Social Convergency. 5th International ISCRAM Conference, Washington.

Irina, S., L. Palen, et al. (2008). Finding Community Through Information and Communication Technology During Disaster Events. CSCW'08. San Diego, California, USA.

Kapucu, N. (2007). "Non-profit response to catastrophic disasters." Disaster Prevention and Management 16(4).

Knaus, C. (2011). Facebook and Twitter the new centres of disaster relief and connection. The Age. Brisbane.

Liu, B. S., L. Palen, et al. (2008). In Search of the Bigger Picture: The Emergent Role of On-Line Photo Sharing in Times of Disaster. 5th International 
ISCRAM Conference Washington, DC, USA.

Macnamara, J. (2003). "Media content analysis: Its uses; benefits and best practice methodology." Asia Pacific Public Relations Journal 6(1): 34.

McBryde, E. (2011). Facebook disaster page saved lives. The Queensland Times. Brisbane.

McEntire, D. A. (2002). "Coordinating multiorganisational responses to disaster: lessons from the March 28, 2000, Fort Worth tornado." Disaster Prevention and Management 11(5): pp.369 - 379.

McMichael, A. J., D. H. Campbell-Lendrum, et al. (2003). Climate Change and Human Health: Risks and Responses. Geneva, World Health Organization.

Midena, K. (2011). Disasters taint Queensland Tourism Million Dollar Memo campaign. The Australian. Brisbane, News Limited.

Paton, D. and D. Johnston (2001). "Disasters and Coomunities: Vulnerability, Resilience and Preparedness." Disaster Prevention and Management 10(4): pp.270-277.

Perez-Lugo, M. (2004). "Media Uses in Disaster Situations: A new Focus on the Impact Phase." Sociological Inquiry 74(2): pp.20-225.

Quarantelli, E. L. (1996). "The Future Is Not the Past Repeated: Projecting Disasters in the 21st Century from Current Trends." Journal of Contingencies and Crisis Management 4(4): pp.220-240.

Queensland Government (2012). Disaster Management Arrangements. D. Management. Brisbane.

Queensland Police (2011). Disaster Management and Social Media - A Case Study. Queensland Police Service. Brisbane, Queensland Police.

Riddell, E., A. Rock, et al. (2010). Strengthening Youth Resilience to Natural Disaster with Smartphine
Technology. Brisbane, The University of Queensland.

Ritchie, W. B. (2004). "Chaos, crises and disasters: a strategic approach to crisis management in the tourism industry." Tourism Management 25(6): pp.669-683.

Rive, G., J. Thomas, et al. (2012). Social Media in an Emergency: Developing a Best Practice Guide. K. Mora. Gracefield, Opus International Consultants Limited

Saleem, K., S. Luis, et al. (2008). Towards a business continuity information network for rapid disaster recovery. Proceedings of the 2008 international conference on Digital government research. Montreal, Canada, Digital Government Society of North America: pp.107-116.

Samarajiva, R. (2005). "Mobilizing Information and Communications Technologies for Effective Disaster Warning: Lessons from the 2004 Tsunami." New Media and Society 7(6): pp.731-747.

Shaluf, I. M., F. R. Ahmadun, et al. (2003). "Technological Disaster's Criteria and Models." Disaster Prevention and Management 12(4): pp.305-311.

Spiegel, B. P. (2005). "Differences in World Responses to Natural Disasters and Complex Emergencies." Journal of the American Medical Association 293(15).

Stemler, S. (2001). "An Overview of Content Analysis." Practical Assessment, Research \& Evaluation 7(17): 9.

Sykes, E. (2011) "Emergency 2.0: How Social Media proved itself in the Queensland Floods.".

Sykes, E. (2011). Emergency 2.0: How Social Media proved itself in the Queensland Floods. 610 ABC Brisbane. Brisbane.

Taylor, A. (2011). Facebook the best lifeline in emergency. The Sydney Morning Herald. Sydney, Fairfax Media.

Taylor, M., G. Wells, et al. (2012). "The Role of Social Media as Psychological First Aid as a Support to Community 
The role of Social media during Queensland floods / Ahmed et al.

Resilience Building." The Australian Journal of Emergency Management 27(1).

Taylor, M., G. Wells, et al. (2012). "The role of social media as psychological first aid as a support to community resilience building." The Australian Journal of Emergency Management 27(1).

Toft and S. Reynolds (1994). "Learning from Disasters." Butterworth-Heinemann.

Underwood, S. (2010). "Improving disaster management." Commun. ACM 53(2): pp. 18-20.

Vieweg, S., L. A. Hughes, et al. (2007). Microblogging During Two Natural Hazards Events: What Twitter May Contribute to Situational Awareness. Crisis Informatics. Atlanta, GA, USA.
Waugh, W. L. and G. Streib (2006). "Collaboration and Leadership for Effective Emergency Management." Public Administration Review 66: pp. 131-140.

Widmer, G. (2003). Aid after Natural Disasters: Interaction between International and Local Actors: A Case Study of the Floods in Mozambique. E. a. P. S. Departments. St Louis, MO., Washington University,.

Yanay, U., S. Benjamin, et al. (2011). "Networking emergency teams in Jerusalem." Disaster(1): pp.183-199.

\section{About Authors}

Ashir Ahmed is a lecturer of Information Systems at Swinburne University of Technology, Australia. He earned his PhD degree in Information Systems from Monash University, Australia. His research interests focus on the role of social media in various contexts including Disaster Management and Small and Medium Enterprises (SMEs). He has published in the area of technology adoption (such as Radio Frequency Identification (RFID)) in disaster management that appeared in International Conference on Information Systems (ICIS), European Conference on Information Systems (ECIS), Hawaii International Conference on System
Sciences (HICSS) and Pacific Asia Conference on Information Systems (PACIS).

Sukunesan Sinnappan Dr. Sinnappan is a Senior Lecturer in Business Designs and Systems and is currently attached to the Information Systems department at Swinburne University of Technology. His research interests are mainly in areas related to social media applications and eBusiness. He has authored more than 50 research articles including refereed journals, international conferences and book chapters apart from various international presentations. 